\title{
Metode Numerik FDTD dengan Non-Uniform Grid untuk Solusi Persamaan Schrödinger
}

\author{
Rohma Yuliani dan I Wayan Sudiarta* \\ Laboratorium Riset Fisika Teori dan Komputasi, Program Studi Fisika, \\ Fakultas MIPA Universitas Mataram, Jalan Majapahit No 62 Mataram 83125
}

Intisari

\begin{abstract}
Pada paper ini, spasi grid yang non-uniform (tidak seragam) digunakan untuk meningkatkan akurasi pada metode finite difference time domain (FDTD). Pada umumnya, metode FDTD menggunakan grid seragam (uniform) sehingga pada kasus dengan perubahan potensial yang besar membutuhkan spasi grid yang cukup kecil dan jumlah grid yang banyak untuk mendapatkan akurasi yang diinginkan. Dengan spasi grid tidak seragam, posisi titik grid disesuaikan dengan perubahan potensial sehingga akurasi tinggi dapat diperoleh tanpa menambah jumlah grid. Pada paper ini, komparasi hasil metode FDTD dengan grid uniform dan non-uniform untuk sistem partikel di dalam potensial konstan (kotak) dan tidak konstan (osilator harmonik) diberikan. Sesuai ekspektasi, hasil numerik menunjukkan bahwa penurunan akurasi diperoleh dengan menggunakan grid non-uniform untuk kasus potensial konstan, tetapi terjadi peningkatan akurasi untuk kasus potensial tidak konstan.
\end{abstract}

Abstract

In this paper, non-uniform grids are used to improve accuracy in the finite difference time domain (FDTD) method. In generally, FDTD method uses a uniform grid so that in the case of potential changes in large wells it requires a fairly small grid and a large number of grid to obtain the desired accuracy. With a non-uniform grid, grid spacing is adjusted to potential changes so that high accuracy can be obtained without increasing the number of grids. In this paper, the comparison of the results of the FDTD method with a uniform and non-uniform grid for a particle in constant and variable potentials is given. As expected, the numerical results indicate that a decrease in accuracy using non-uniform grids is obtained for the constant potential case, but an increase in accuracy for the variable potential case.

Keywords: FDTD Method: Non-Uniform Grid: Schrödinger Equation.

*Corresponding author: wayan.sudiarta@unram.ac.id

http://dx.doi.org/10.12962/j24604682.v16i3.6187

2460-4682 (CDepartemen Fisika, FSAD-ITS

\section{PENDAHULUAN}

Energi dan fungsi gelombang suatu partikel dapat ditentukan dengan menyelesaikan persamaan Schrödinger. Energi dan fungsi gelombang digunakan untuk mendeskripsikan perilaku suatu partikel. Ada banyak cara yang dapat digunakan untuk menyelesaikan persamaan Schrödinger, diantaranya diffusion monte carlo (DMC)[1,2], discretized path integral (DPI) [3], finite difference time domain (FDTD)[4], dan metode elemen hingga (finite element method, FEM) [5,6].

Diantara beberapa metode di atas, metode FDTD telah terbukti dapat menyelesaikan persamaan diferensial secara sederhana. Hal ini dibuktikan dari beberapa hasil penelitian. Diantaranya, penelitian yang dilakukan oleh Sudiarta dan Geldart [4] yaitu memecahkan persamaan Schrödinger menggunakan metode FDTD dengan grid uniform untuk menentukan energi dan fungsi eigen. Selanjutnya, Sudiarta dan Geldart [7] kembali menerapkan metode FDTD grid uniform untuk kasus partikel bermuatan dalam pengaruh medan magnet. Sudiarta dan Geldart [8] menerapkan lagi metode FDTD grid uniform untuk kasus density matrix satu partikel. Sudiarta dan Angraini [9] berhasil mensimulasikan dua elektron yang berintraksi pada potensial quantum dot. Dari beberapa hasil penelitian di atas terbukti bahwa metode FDTD grid uniform dapat digunakan untuk menyelesaikan persamaan diferensial secara sederhana.

Dalam penelitian ini digunakan metode FDTD untuk menyelesaikan persamaan Schrödinger dengan grid nonuniform. Hal ini dilakukan untuk meningkatkan akurasi pada metode FDTD [10]. Pada umumnya, metode FDTD menggunakan grid uniform sehingga pada kasus dengan perubahan sumur potensial yang besar membutuhkan grid yang cukup kecil dan jumlah grid yang banyak untuk mendapatkan akurasi yang diinginkan. Dengan grid non-uniform, spasi grid disesuaikan dengan perubahan potensial sehingga akurasi tinggi dapat diperoleh tanpa menambah jumlah grid. Dengan kata lain menggunakan jumlah grid yang lebih sedikit dapat menghasilkan akurasi yang setara dengan grid uniform dengan jumlah grid yang banyak. Hal ini dapat mengurangi penggunaan komputer memori dan waktu simulasi. 


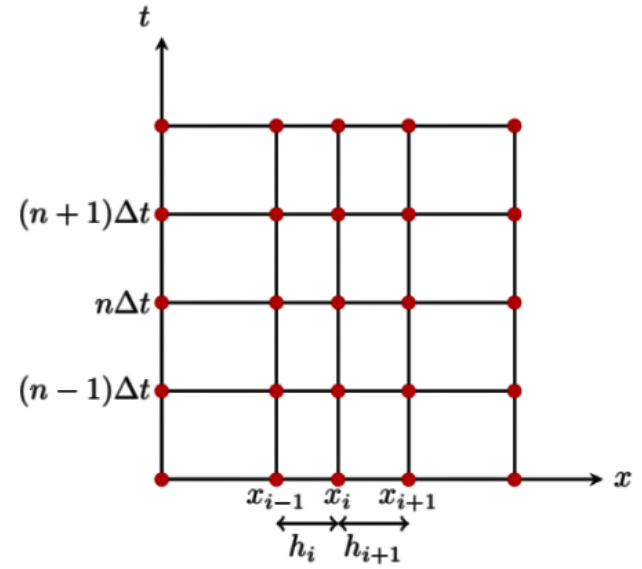

Gambar 1: Posisi grid yang non-uniform dimana jarak antar gridnya tidak sama.

\section{METODOLOGI}

Metode numerik yang digunakan untuk menyelesaikan persamaan Schrödinger yaitu metode FDTD dengan grid nonuniform, dengan bahasa pemrograman C. Mengikuti Sudiarta dan Geldart [4] persamaan diferensial yang digunakan yaitu

$$
\frac{\partial}{\partial t} \Psi(x, t)=-\frac{1}{\hbar} \widehat{H} \Psi(x, t)
$$

dengan operator Hamilton diberikan oleh [11]

$$
\widehat{H}=\left[-\frac{\hbar^{2}}{2 m} \frac{\partial^{2}}{\partial x^{2}}+V(x)\right]
$$

Simulasi fungsi gelombang dengan Pers. (1), akan menghasilkan perilaku peluruhan (decay) fungsi gelombang. Ke- cepatan peluruhan bergantung pada energi keadaan sistem. Karena keadaan dengan energi terendah sistem adalah keadaan dasar, setelah waktu simulasi yang cukup lama, setelah semua keadaan selain keadaaan dasar meluruh, fungsi gelombang yang tersisa adalah fungsi gelombang keadaan dasar

$$
\Psi(x, t)=A e^{-E t / \hbar} \Psi_{\circ}(x)
$$

Koefisien pengali $e^{-E t / \hbar}$ dapat dihilangkan dengan menggunakan kondisi ternormalisasi dari fungsi gelombang, $\left\langle\Psi_{\circ} \mid \Psi_{\circ}\right\rangle$.

Setelah mendapatkan fungsi gelombang dalam keadaan dasar, selanjutnya dilakukan penghitungan energi menggunakan

$$
E_{\circ}=\frac{\left\langle\Psi_{\circ}|\widehat{H}| \Psi_{\circ}\right\rangle}{\left\langle\Psi_{\circ} \mid \Psi_{\circ}\right\rangle}=\frac{\int \Psi_{\circ} * \widehat{H} \Psi_{\circ} d x}{\int\left|\Psi_{\circ}\right|^{2} d x}
$$

Mengikuti prosedur penurunan rumus numerik yang ada di Sudiarta dan Geldart [4] dan menggunakan notasi $\Psi^{n}(i) \equiv$ $\Psi\left(x_{i}, i \Delta t\right)$, pendekatan turunan pertama terhadap waktu dan turunan kedua secara numerik diberikan oleh

$$
\frac{\partial \Psi(x)}{\partial \tau} \approx \frac{\left[\Psi^{n+1}(i)-\Psi^{n}(i)\right]}{\Delta \tau}
$$

Untuk grid non-uniform, turunan terhadap posisi diberikan oleh

$$
\frac{\partial^{2} \Psi}{\partial x^{2}}=\frac{h_{i} \Psi^{n}(i+1)-\left(h_{i}+h_{i+1}\right) \Psi^{n}(i)+h_{i+1} \Psi^{n}(i-1)}{\frac{h_{i} h_{i+1}}{2}\left(h_{i}+h_{i+1}\right)}(6)
$$

dengan $h_{i}=x_{i}-x_{i-1}$ dan $h_{i+1}=x_{i+1}-x_{i}$, ilustrasi penempatan grid non-uniform dapat dilihat pada Gambar 1.

Dengan satuan alami sehingga nilai $\hbar=m=1$, setelah substitusi Pers. (5) dan Pers. (6) ke Pers.(1) diperoleh persamaan numerik:

$$
\Psi^{n+1}(i)=\alpha \Psi^{n}(i)+\beta\left[\frac{h_{i} \Psi^{n}(i+1)-\left(h_{i}+h_{i+1}\right) \Psi^{n}(i)+h_{i+1} \Psi^{n}(i-1)}{h_{i} h_{i+1}\left(h_{i}+h_{i+1}\right)}\right]
$$

dengan koefisien $\alpha$ dan $\beta$ yaitu

$$
\alpha=\frac{1-\frac{\Delta t}{2} V(i)}{1+\frac{\Delta t}{2} V(i)}, \quad \beta=\frac{\Delta t}{1+\frac{\Delta t}{2} V(i)}
$$

Energi keadaan dasar dapat dihitung dengan

$$
E_{\circ}=\frac{1}{\Sigma_{i} \Psi(i)^{2}} \Sigma_{i}\left\{V(i) \Psi(i)^{2}-\Psi(i)\left[\frac{h_{i} \Psi^{n}(i+1)-\left(h_{i}+h_{i+1}\right) \Psi^{n}(i)+h_{i+1} \Psi^{n}(i-1)}{h_{i} h_{i+1}\left(h_{i}+h_{i+1}\right)}\right]\right\}
$$

Berdasarkan analisis numerik untuk Pers.(6) menggunakan pendekatan Taylor, diperoleh bahwa pendekatan menggunakan grid non-uniform memiliki orde akurasi yang lebih ren- dah $(\mathrm{O}(\mathrm{h}))$ daripada grid uniform $\left(\mathrm{O}\left(h^{2}\right)\right)$ dengan spasi grid yang sama. Kontribusi kesalahan pada hasil metode FDTD dengan grid uniform maupun non-uniform bergantung pada 


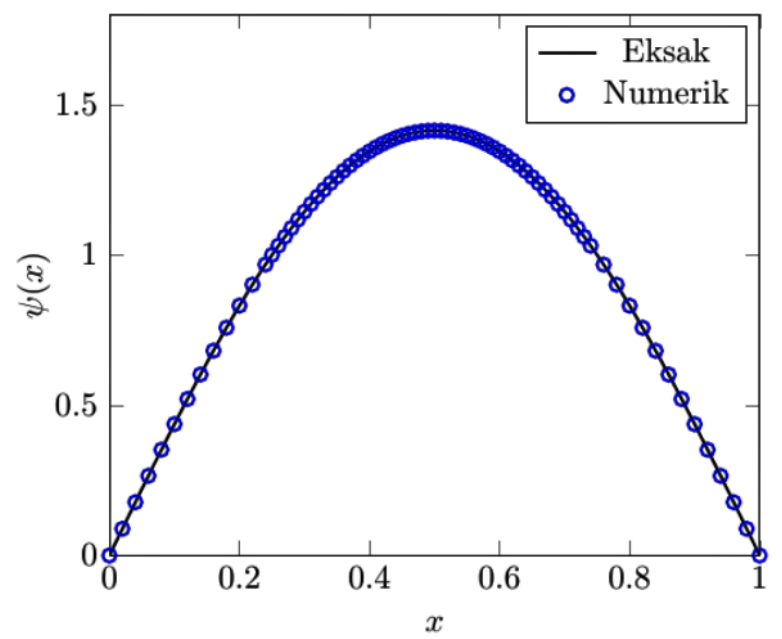

Gambar 2: Grafik fungsi gelombang untuk kasus potensial kotak dengan panjang ruang simulasi $(\mathrm{L})=1$.

perubahan potensial dan besar nilai fungsi gelombang pada posisi gridnya. Pada kasus dengan perubahan potensial, grid non-uniform dapat disesuaikan dengan potensialnya sehingga menghasilkan akurasi yang lebih tinggi.

\section{HASIL DAN PEMBAHASAN}

Digunakan beberapa sistem kuantum untuk memvalidasi hasil yang diperoleh, diantaranya potensial kotak dan osilator harmonik. Ditampilkan nilai energi dasar dan grafik fungsi gelombang dari berbagai sistem kuantum yang digunakan. Yang menjadi tantangannya dalam menyelesaikan kasus dengan grid non-uniform adalah bagaimana mengatur gridnya, sehingga mendapatkan hasil yang akurat.

\section{Potensial kotak}

Dengan menggunakan potensial kotak, dimana $\mathrm{V}(\mathrm{x})=0$ untuk $0<1$ dan $\mathrm{V}(\mathrm{x})=] \operatorname{sim}$ untuk $\mathrm{x}>1$ dan $\mathrm{x}<0$. Fungsi eigen dari kasus ini adalah

$$
\Psi_{n}(x)= \begin{cases}\sqrt{2} \sin (n \pi x), & \text { di dalam sumur } \\ 0, & \text { di luar sumur. }\end{cases}
$$

dan energinya diberikan oleh

$$
E_{n}=\frac{(n \pi)^{2}}{2}
$$

dengan $\mathrm{n}=1,2,3, \ldots$ bilangan positif. Dalam simulasi digunakan parameter panjang ruang simulasi $(\mathrm{L})=1$ dan jumlah gridnya $(\mathrm{Nx})$ sebanyak 75 . Penggunaan metode FDTD grid non-uniform artinya bahwa dapat diatur jarak antar grid sedemikian hingga jarak antar grid tidak lagi sama, hal ini dilakukan untuk meningkatkan akurasi yang diperoleh. Dimana, jarak antar grid sebesar 0,02 untuk grid pertama

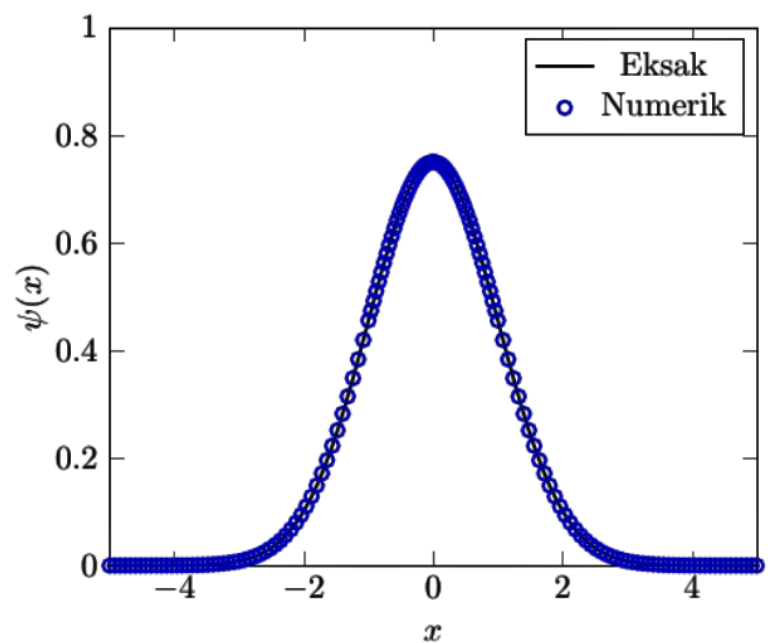

Gambar 3: Perbandingan hasil numerik dan analitik fungsi gelombang untuk kasus osilator harmonik.

hingga 13 dan grid 63 hingga 75, sedangkan untuk grid 13 hingga 62 digunakan jarak antar grid sebesar 0,01. Dilakukan juga perhitungan dengan FDTD grid uniform dengan jarak antar grid seragam yaitu 0,013333 . Sehingga diperoleh grafik fungsi gelombang dalam keadaaan dasar dengan FDTD non-uniform yang dapat dilihat pada Gambar 2 dan nilai energi dasar pada Tabel I. Jika dibandingkan perbedaan energi $(\Delta E)$ hasil perhitungan numerik dan eksak dengan grid uniform dan non-uniform, terlihat bahwa hasil untuk kasus potensial kotak grid non-uniform sebesar 0,002156 dan grid uniform sebesar 0,000721. Hal ini berarti bahwa untuk kasus potensial konstan tingkat akurasi yang diperoleh dengan grid non-uniform lebih rendah dibanding dengan grid uniform (dengan jumlah grid ( $\mathrm{Nx}$ ) yang sama).

\section{Osilator harmonik}

Untuk kasus osilator harmonik satu dimensi, digunakan potensial yang diberikan oleh

$$
V(x)=\frac{1}{2} k x^{2}
$$

Panjang ruang komputasi yang digunakan sebesar 10 dengan jarak antar grid nya tidak sama. Proses yang dilakukan sama seperti pada kasus potensial kotak. Adapun hasil numerik dan eksak fungsi gelombang untuk kasus osilator harmonik dapat dilihat pada Gambar 3. Nilai energi dasar untuk kasus osilator harmonik terdapat pada Tabel I. Jika dibandingkan hasil energi yang diperoleh dengan grid uniform dan non uniform seperti yang ditunjuk pada Tabel I, dapat ditunjukkan bahwa grid non uniform memberikan hasil yang lebih mendekati nilai eksak. 
TABEL I: Perbandingan hasil perhitungan energi dasar untuk kasus potensial kotak dan osilator harmonik dengan grid uniform dan non-uniform.

\begin{tabular}{|c|c|c|c|c|c|}
\hline \multirow[t]{2}{*}{ Potensial } & \multirow[t]{2}{*}{ Eksak } & \multicolumn{2}{|c|}{ FDTDGrid } & \multirow{2}{*}{$\begin{array}{c}\Delta \mathrm{E} \\
\text { non-uniform }\end{array}$} & \multirow[b]{2}{*}{ uniform } \\
\hline & & non-uniform & uniform & & \\
\hline Kotak & 4,934802 & 4,932646 & 4.934081 & 0,002156 & 0,000721 \\
\hline Osilator & & & & & \\
\hline Harmonik & 0,5 & 0,499742 & 0,499687 & 0,000258 & 0,000312 \\
\hline
\end{tabular}

\section{SIMPULAN}

Metode FDTD grid non-uniform telah diberikan untuk menyelesaikan persamaan Schrödinger untuk kasus potensial kotak dan osilator harmonik. Metode FDTD grid non-uniform bisa digunakan untuk menyelesaikan berbagai sistem kuantum dengan mudah. Hasil numerik berupa energi dasar dari kasus yang telah diberikan menunjukkan bahwa untuk kasus potensial osilator harmonik penggunaan grid non-unifom da- pat meningkatkan akurasi jika dibandingkan dengan grid uniform dengan jumlah grid yang sama.

\section{Ucapan Terima Kasih}

Penulis berterimakasih kepada dosen dan mahasiswa di peminatan teori dan komputasi yang telah membantu dalam penelitian ini.
[1] I. Kosztin, F. Byron, dan S. Klaus, "Introduction to the diffusion monte carlo method", American Journal of Physics, vol. 64, pp. 633-644, 1996.

[2] J. Boronat, "Diffusion Monte Carlo for excited states: Aplication to liquid helium", Navarro Journal, vol. 510, pp. 359, 2007.

[3] D. Thirumalai, E.J. Bruskin, dan B.J. Berne, "An iterative scheme for the evaluation of discretized path integrals", Journal of Chemical Physics, vol. 79, pp. 5063, 1983.

[4] I.W. Sudiarta, and D.J.W. Geldart, "Solving the schrödinger equation using the finite difference time domain method", Journal of Physics A: Mathematical and Theoretical, vol. 40, pp. 1885-1896, 2007

[5] Z. Tian, Y. Chen, Y. Huang, dan J. Wang, "Two-grid for the two-dimensional time-dependent Schrdinger equation by the finite element method", Journal Computers and Mathematics with Applications, pp. 1-11, 2008.

[6] W. Cai, D. He, K. Pan, "A linearized energy-consevative finite element method for the non linear Schrdinger equation with wave operator", Journal of Applied Numerical Mathematics, vol. 140, pp. 183-198, 2019.

[7] I.W. Sudiarta, and D.J.W. Geldart, "Solvig the schrodinger equation for a charge particle in a magnetic field using the finite difference time domain method", Physics Letters A, vol. 372, pp. 3145-3148, 2008.

[8] I.W. Sudiarta, and D.J.W. Geldart, "The finite difference time domain method for computing the single particle density matrix", Journal of Physics A: Mathematical and Theoretical, vol. 42, pp. 1-20, 2009.

[9] I.W. Sudiarta, and L.M. Angraini, "The finite difference time domain (FDTD) method to determine energies and wave functions of two-electron quantum dot", Proceedings of the 3rd International Symposium on Current Progress in Mathematics and Science, vol. 2023, 2018, pp. 1-7.

[10] J. Bodeau, G. Riboulet, and T. Roncalli, "Non uniform grids for PDE in finance", SSRN Electronic Journal, pp. 1-23, 2000.

[11] B.H. Bransden, and C.J. Joachain, "The Schrödinger equation", Quantum Mechanics, 2th ed. Harlow, England: Pearson Education, ch. 3, sec. 1, pp. 85, 1926. 